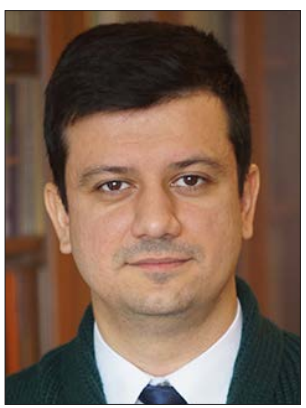

Artur V. Timenko тіменко Артур Валентинович

УДК 004.052.42

\title{
ON THE ASPECTS OF IOT PROTOCOLS SPECIFICATION AND CHECKING
}

\section{ЩОДО АСПЕКТІВ СПЕЦИФІКАЦІЇ І ПЕРЕВІРКИ ПРОТОКОЛІВ ІНТЕРНЕТУ РЕЧЕЙ}

DOI https://doi.org/10.15589/smi2019.2(12).4

\section{Artur V. Timenko}

\author{
Artur V. Timenko \\ Тіменко Артур Валентинович, асистент \\ timenko.artur@gmail.com \\ ORCID: 0000-0002-7871-4543
}

\author{
National University «Zaporizhzhia Polytechnic», Zaporizhzhia \\ Національного університету «Запорізька політехніка», м. Запоріжжя
}

\begin{abstract}
Modern level of diverse software systems complexity stipulates the engineering process to be adapted and refined appropriately. The demonstrative examples of such systems are the ones from the Internet of Things domain that, in particular, imply the usage of specialized communication protocols. The concept of the Internet of Things encompasses the billions of heterogeneous smart devices communicating to each other through different protocols. Taking into consideration the variation of communication protocols and its implementations, the interoperability problem arises. Moreover, it should be noted that during the designing of diverse systems, the safety-critical ones in particular, the practice of formal methods usage, especially the model checkers, is becoming more and more popular. The work is addressed to solving the interoperability problem of the Internet of Things domain by way of automated model checking.

Goal - to propose an approach to solving the interoperability problem in the Internet of Things domain by way of model checking method usage. The technique applied is as follows: synthesize the abstract specification first, and then this specification should be detailed and formally checked in an automated manner. Results obtained - an approach to checking the interoperability between the components of the Internet of Things system has been proposed. The approach is based on automated formal verification of communication protocols. Synthesis of MQTT protocol specification has been considered as a case study. The novelty of work is about the interpretation of interoperability checking problem from the viewpoint of consistency at communication protocols level. The practical value of the results obtained is about the possibility of application of the approach proposed in order to exclude the unexpected scenarios of the Internet of Things System's components communication, communication failures in particular.
\end{abstract}

Key words: IoT, protocol, specification, verification, model checking, interoperability, QoS, TLA.

Анотація. Сучасний рівень складності різноманітних програмних систем зумовлює потребу адаптації та доопрацювання процесу розроблення таких систем належним чином. Показовими прикладами останніх $є$ системи, побудовані згідно з концепцією Інтернету речей, що, зокрема, передбачає застосування спеціалізованих протоколів взаємодії компонентів. Концепція Інтернету речей охоплює мільярди різнорідних «розумних» пристроїв, що взаємодіють один 3 одним на основі різноманітних протоколів. 3 огляду на варіативність протоколів взаємодії та їх реалізацій виникає проблема сумісності таких пристроїв. Разом із цим варто відзначити, що під час проектування різного роду систем, наприклад систем критичного призначення, все більшого поширення набуває використання формальних методів, зокрема методів перевірки на моделі. Робота адресується вирішенню проблеми перевірки сумісності компонентів систем Інтернету речей шляхом автоматизованого застосування методів перевірки на моделі.

Мета роботи - запропонувати підхід до вирішення проблеми перевірки сумісності компонентів систем Інтернету речей за рахунок застосування методу перевірки на моделі. Методика полягає в наступному: спочатку синтезується абстрактна специфікація, потім ця специфікація деталізується і перевіряється методом перевірки на моделі в автоматизованому режимі. Як результат запропоновано підхід до перевірки сумісності компонентів систем Інтернету речей, що полягає в автоматизованій формальній верифікації протоколів взаємодії. Синтез специфікації протоколу МQTT згідно з запропонованим підходом розглядається як тематичне дослідження. Наукова 
новизна роботи полягає в інтерпретації проблеми перевірки сумісності компонентів систем Інтернету речей 3 позиції узгодженості взаємодії компонентів на рівні застосовуваних протоколів взаємодії. Практичне значення одержаних результатів полягає в можливості застосування запропонованого підходу з метою уникнення непередбачуваних сценаріїв взаємодії компонентів систем Інтернету речей, зокрема відмов взаємодії.

Ключові слова: ІоТ, протокол, специфікація, верифікація, перевірка на моделі, сумісність, QoS, TLA

\section{References}

[1] Li, S., Xu, L. D., \& Zhao, S. (2018). 5G Internet of Things: a survey. Journal of Industrial Information Integration, 10, 1-9.

[2] Al-Fuqaha, A., Guizani, M., Mohammadi, M., Aledhari, M., \& Ayyash, M. (2015). Internet of things: a survey on enabling technologies protocols and applications. IEEE Communications Surveys \& Tutorials, 17(4), 2347-2376.

[3] Bormann, C., Castellani, A. P., \& Shelby, Z. (2012). CoAP: an application protocol for billions of tiny Internet nodes. IEEE Internet Computing, 16(2), 62-67.

[4] Karagiannis, V., Chatzimisios, P., Vazquez-Gallego, F., \& Alonso-Zarate, J. (2015). A survey on application layer protocols for the internet of things. Transaction on IoT and Cloud Computing, 3(1), 11-17.

[5] Al-Fuqaha, A., Khreishah, A., Guizani, M., Rayes, A., \& Mohammadi, M. (2015). Toward better horizontal integration among iot services. IEEE Communications Magazine, 53(9), 72-79.

[6] Thangavel, D., Ma, X., Valera, A., Tan, H.-X., \& Tan, C. K.-Y. (April 2014). Performance evaluation of MQTT and CoAP via a common middleware. Paper presented at 2014 IEEE Ninth Int. Conf. on Intelligent Sensors, Sensor Networks and Information Processing, Singapore.

[7] Information technology - Message Queuing Telemetry Transport (MQTT) v3.1.1, ISO/IEC 20922:2016, 2016. Retrieved from: https://www.iso.org/standard/69466.html.

[8] Organization for the advancement of structured information standards, MQTT version 5.0, OASIS, Candidate OASIS Standard 01, 31 October 2018. Retrieved from: https://docs.oasis-open.org/mqtt/mqtt/v5.0/mqtt-v5.0.html.

[9] Light, R. A. (2017). Mosquitto: server and client implementation of the MQTT protocol. Journal of Open Source Software, 2(13), 1-2.

[10] Johnson, J. E., Langworthy, D. E., Lamport, L., \& Vogt, F. H. (2004). Formal specification of a web services protocol. Electronic Notes in Theoretical Computer Science, 105, 147-158.

[11] Hunkeler, U., Truong, H. L., \& Stanford-Clark, A. (Jan. 2008). MQTT-S - A publish/subscribe protocol for wireless sensor networks. Paper presented at Proc. 2008 3rd International Conf. on Communication Systems Software and Middleware and Workshops, Bangalore, India.

[12] Houimli, M., Kahloul, L., \& Benaoun, S. (Dec. 2017). Formal specification verification and evaluation of the mqtt protocol in the internet of things. Paper presented at 2017 Int. Conf. on Mathematics and Information Technology, Adrar, Algeria.

[13] Lee, S., Kim, H., Hong, D-K., \& Ju, H. (Jan. 2013). Correlation analysis of MQTT loss and delay according to QoS level. Paper presented at The Int. Conf. 2013 on Information Networking, Bangkok, Thailand.

[14] Rodríguez, A., Kristensen, L. M., \& Rutle, A. (Jun. 2018). On modelling and validation of the MQTT IoT protocol for M2M communication. Paper presented at Int. Workshop on Petri Nets and Software Engineering, Bratislava, Slovakia.

[15] Diwan, M. \& D'Souza, M. (Oct. 2017). A framework for modeling and verifying IoT communication protocols. Paper presented at Third Int. Symposium on Dependable Software Engineering: Theories, Tools, and Applications, Changsha, China.

[16] Abrial, J-R., Butler, M., Hallerstede, S., Hoang, T. S., Mehta, F., \& Voisin, L. (2010). Rodin: an open toolset for modelling and reasoning in Event-B. Int. Journal on Software Tools for Technology Transfer, 12(6), 447-466.

[17] Govindan, K. \& Azad, A. P. (Jan. 2015). End-to-end service assurance in IoT MQTT-SN. Paper presented at 2015 12th Annual IEEE Conf. on Consumer Communications and Networking, Las Vegas, NV, USA.

[18] Aziz, B. (2016). A formal model and analysis of an IoT protocol. Ad Hoc Networks, 36(1), $49-57$.

[19] Tappler, M., Aichernig, B. K., \& Bloem, R. (March 2017). Model-based testing IoT communication via active automata learning. Paper presented at 2017 IEEE International Conference on Software Testing, Verification and Validation, Tokyo, Japan.

[20] Vattakunnel, A. J., Kumar, N. S., \& Kumar, G. S. (2016). Modelling and verification of CoAP over routing layer using SPIN model checker. Procedia Computer Science, 93, 299-308.

[21] Lamport, L. (2002). Specifying systems: The TLA+language and tools for hardware and software engineers. Boston : Addison-Wesley.

[22] Newcombe, C., Rath, T., Zhang, F., Munteanu, B., Brooker, M., \& Deardeuff, M. (2015). How Amazon web services uses formal methods. Communications of the ACM, 58(4), 66-73.

[23] Clarke, E. M., Grumberg, O., \& Peled, D. A. (2001). Model checking. Massachusetts : MIT Press. 
[24] Shkarupylo, V. \& Polska, O. (Feb. 2018). The approach to SDN network topology verification on a basis of Temporal Logic of Actions. Paper presented at 14th Int. Conf. on Advanced Trends in Radioelectronics, Telecommunications and Computer Engineering, Lviv-Slavske, Ukraine.

[25] Shkarupylo, V., Kudermetov, R., Golub, T., Polska, O., \& Tiahunova, M. (Oct. 2018). Towards model checking of the Internet of Things solutions interoperability. Paper presented at 2018 IEEE Int. Scientific and Practical Conf. on Problems of Infocommunications. Science and Technology, Kharkiv, Ukraine.

[26] Lamport L. (Aug. 2009). The PlusCal algorithm language. Paper presented at 6th Int. Colloquium on Theoretical Aspects of Computing, part of LNCS, Kuala Lumpur, Malaysia.

[27] Shkarupylo, V.V., Tomicic, I., \& Kasian, K.M. (2016). The investigation of TLC model checker properties. Journal of Information and Organizational Sciences, 40(1), 145-152.

[28] Shkarupylo, V.V., Tomicic, I., Kasian, K.M., \& Alsayaydeh, J. A.J. (2018). An approach to increase the effectiveness of TLC verification with respect to the concurrent structure of TLA+ specification. International Journal of Software Engineering and Computer Systems, 4(1), 48-60.

Постановка задачі. На сході налічується значна кількість пристроїв, підключених до мережі Інтернет та залучених до взаємодії типу М2M (machineto-machine). Очікується, що загальна кількість таких пристроїв до 2020 року перевищить позначку у 20 мільярдів [1]. Таку концепцію прийнято називати Iнтернетом речей (IoT, Internet of Things). У такому контексті є нагальна потреба у вдосконаленні наявних та розробленні нових технологій і протоколів, що дають можливість реалізувати успішну взаємодію пристроїв з погляду сумісності, зменшення трафіку тощо. До цього часу було докладено багато зусиль у цьому напрямі. Наприклад, впроваджено протокол IPv6 та технологію RFID (радіочастотна ідентифікація) [2]. Незважаючи на це, існує потреба в ефективних протоколах взаємодіі, які б враховували характерні аспекти предметної області Інтернету речей - автономність пристроїв, що взаємодіють, динамічну природу конфігурацій систем на їх основі, строгі вимоги до трафіку, низькі обчислювальні можливості пристроїв, орієнтацію на бездротовий зв'язок тощо. Для інтеграції ІоТ-інфраструктури до складу наявних мереж застосовуються відповідні протоколи. Демонстративним прикладом є протокол MQTT (Message Queue Telemetry Transport), що передбачає використання поверх протоколу ТСР. Альтернативою $є$ протокол CoAP (Constrained Application Protocol), що передбачає використання поверх UDP [3; 4]. Окрім названих, $\epsilon$ чимало ІоТ-протоколів різних рівнів: прикладного рівня (XMPP, DDS тощо), управління (OMA DM, CPE WAN тощо), зв'язку (Cellular, Zigbee тощо). Вичерпний порівняльний аналіз протоколів вже було проведено [5].

Доцільність застосування того чи іншого протоколу частково визначається конфігурацією мережі. Наприклад, оцінка продуктивності протоколів MQTT та CoАР показала, що використання протоколу MQTT супроводжується меншими затримками, а CoAP - меншими витратами трафіку [6]. Водночас рівень придатності певного протоколу до заданого сценарію застосування регламентується, зокрема, функціоналом, окресленим у специфікації протоколу. Наприклад, протокол МQTT з червня 2016 року став стандартом ISO (версія 3.1.1) - ISO / IEC 20922: 2016 [7]. Крім того, остання специфікація MQTT (версія 5.0), розміщена консорціумом OASIS (Організація з розвитку стандартів структурованої інформаціі), пропонує багато нових функцій, наприклад, підвищення масштабності, покращення ефективності та механізму повідомлення про помилки [8].

Сучасний процес розробки нових специфікацій протоколу та/або уточнення вже наявних тісно пов'язаний із широким використанням формальних методів. Нижче наводяться цілі, які при цьому ставляться:

- перевірка відповідності реалізації певних протоколів специфікаціям, наприклад, реалізації Moshquitto Server i Client протоколу MQTT, написаних мовою програмування C / C ++[9];

- $\quad$ перевірка коректності безпосередньо специфікації протоколу. Було продемонстровано, що формальна верифікація специфікації протоколу методом перевірки на моделі може виявити непередбачені сценарії функціонування. Наприклад, протокол Web Services Atomic Transactions був перевірений за допомогою методу перевірки на моделі TLC (TLAChecker) на основі темпоральної логіки TLA (Temporal Logic of Actions) [10].

Ця стаття присвячена, зокрема, аналізу підходів до використання формальних методів по відношенню до протоколів ІоТ. На основі отриманих результатів, акцентуючи увагу на проблемі сумісності компонентів ІоТ-системи, в роботі ставиться завдання створення підходу до синтезу та верифікації специфікацій протоколів ІоТ, з метою вирішення проблеми перевірки сумісності компонентів ІоТ-системи як проблеми перевірки узгодженості взаємодії останніх на рівні протоколів взаємодії. За основу відповідного тематичного дослідження береться специфікація протоколу MQTT.

Решта статті структурована таким чином. У наступному розділі наводиться коротка характеристика протоколу MQTT, проводиться аналіз останніх досліджень і публікацій. Далі роз'яснюється запропонований підхід. Наприкінці наводяться висновки 3 роботи.

Аналіз останніх досліджень і публікацій. Протокол MQTT - це протокол рівня додатків з низьким ступенем накладних витрат, заснований на обміні бінарними повідомленнями. Функціонує поверх стеку 
протоколів ТCP / IP. Набув широкого поширення завдяки відкритості специфікацій і відносній простоті реалізації.

Протокол базується на моделі видавець-абонент (publisher-subscriber): використовуються поняття видавець, брокер та абонент (рис. 1).

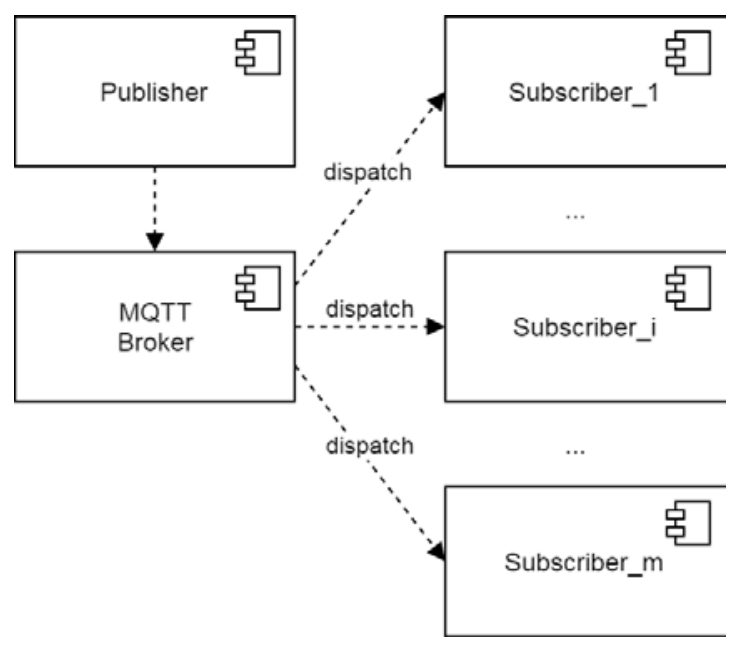

Рис. 1. Концептуальна схема взаємодії згідно з протоколом MQTT

Протокол підтримує три рівні якості послуг (QoS): «не більше одного разу» (рівень 0), «принаймні один раз» (рівень 1) і «рівно один раз» (рівень 2).

Завдяки набутій популярності є багато модифікацій протоколу MQTT, наприклад, розширення MQTT-S, призначене для пристроїв, що живляться від акумулятора і функціонують у бездротових сенсорних мережах [11].

Підходи до використання формальних методів 3 метою верифікації протоколів ІоТ відрізняються доволі суттєво. Запропоновано їх згрупувати таким чином:

- $\quad$ підходи, спрямовані на оцінку ефективності протоколу - група 1;

- $\quad$ підходи, орієнтовані на перевірку проектних рішень та впровадження протоколів - група 2.

Представники першої групи:

- для оцінки працездатності протоколу MQTT запропонована методика перевірки ймовірнісної моделі на основі інструментарію UPPAAL SMC [12];

- підхід, спрямований на кореляційний аналіз втрат та затримок протоколу МQTT відповідно до рівня QoS. Одержані результати показали, що залежно від типу мережі (дротова / бездротова) затримки зв'язку та втрати пакетів відрізняються приблизно в десять разів [13].

Представники другої групи:

- для виявлення неоднозначних фрагментів специфікацій, що потенційно можуть призвести до некоректних реалізацій протоколу МQTT було використано математичний апарат кольорових мереж Петрі (Coloured Petri Nets, CPNs) [14]. Для зниження ефекту розростання простору пошуку було застосовано інкрементний підхід до перевірки на моделі;
- запропоновано підхід на основі використання формального методу Event-B [15], що полягає у використанні інструментарію Rodin [16]. Темпоральні властивості представлено на основі логіки LTL (Linear Temporal Logic). Підхід застосовано по відношенню до протоколів MQTT, MQTT-SN (Message Queue Telemetry Transport Protocol Sensors) [17] i CoAP;

запропоновано формальну модель протоколу MQTT 3.1 на основі алгебри процесів [18]. Було показано, що рівень 2 семантики QoS визначено неоднозначно, що може стати джерелом помилок;

- $\quad$ альтернативний підхід базується на виведенні моделей із реалізацій протоколів МQTT та перехресній перевірці їх відповідності [19]. Було заявлено, що лише в одній (з п’яти) реалізацій протоколу не виявлено помилкової поведінки;

- запропоновано метод синтезу компактних формальних моделей по відношенню до протоколу CoAP [20]. Для перевірки запропонованого методу використано реалізацію методу перевірки на моделі SPIN по відношенню до специфікацій на мові PROMELA.

Підходи другої групи можна узагальнити таким чином:

- результати формальної верифікації протоколів значним чином різняться залежно від використовуваних формалізму, моделі та/або методу. Така ситуація породжує питання стосовно адекватності використовуваних формальних моделей та коректності реалізації застосовуваних методів;

- припущення стосовно коректності специфікацій протоколів будуються на основі обраного рівня абстрактності формальних моделей. Цей фактор посилює актуальність питання перевірки адекватності формальних моделей.

Аналізуючи підходи першої і другої розглянутих груп, можна дійти такого висновку: відкритою є проблема вибору достатнього рівня деталізації формальних моделей, із збереженням їх адекватності.

Мета дослідження. Мета роботи полягає в наступному: запропонувати підхід до вирішення проблеми перевірки сумісності компонентів систем Інтернету речей за рахунок застосування методу перевірки на моделі.

Методи, об'скт та предмет дослідження. Методи дослідження: сімейство формальних методів - методи перевірки на моделі; структура Кріпке; методи імітаційного моделювання.

Об'єкт дослідження - процеси синтезу формальних специфікацій і автоматизованої їх верифікації методами перевірки на моделі.

Предмет дослідження - моделі і методи формальних специфікації і верифікації.

Основний матеріал. Структура Кріпке як аналітичне представлення.

Як основа запропонованого підходу була використана темпоральна логіка дій (TLA) [21]. Завдяки своїй математичній строгості вона дозволяє задавати 
бажану поведінку жорстким, компактним та легко налаштованим способом. Більше того, TLA та відповідні формалізми TLA+, PlusCal, а також метод перевірки на моделі TLC (TLA checker) широко використовуються в різних сценаріях, наприклад, для перевірки проектних рішень Amazon Web Services [22].

Для опису пропонованого підходу застосуємо структуру Кріпке на множині атомарних висловлювань $A P[23]$ :

$$
M=\left\langle S,\left\{s_{0}\right\}, R, L\right\rangle,
$$

де $S$ - кінцевий набір станів, $s_{0} \in S$ - початковий стан, $R \subseteq S^{2}-$ множина переходів, $L: S \rightarrow 2^{A P}-$ функція маркування станів.

Скористаємось концептом «дії» (булева функція, яка відповідає істинності відповідного переходу $\left(s, s^{\prime}\right) \in R$, де $s \in S-$ деякий поточний стан, $s^{\prime}=R(s) \in S-$ відповідний наступний стан [21]).

Маніпуляція зі змінними стану.

Для опису запропонованого підходу розглянемо сценарій обміну повідомленнями другого рівня QoS протоколу MQTT. Виокремимо чотири типи повідомлень. Множина змінних стану, що представляють типи повідомлень, формується таким чином:

$$
V=\left\{v_{1}, v_{2}, v_{3}, v_{4}\right\},
$$

де $v_{1} \in V$ - повідомлення "опублікувати QoS 2", $v_{2} \in V$ - повідомлення PUBREC, $v_{3} \in V$ - повідомлення PUBREL, $v_{4} \in V$ - повідомлення PUBCOMP. Діаграма послідовностей наведена на рис. 2.

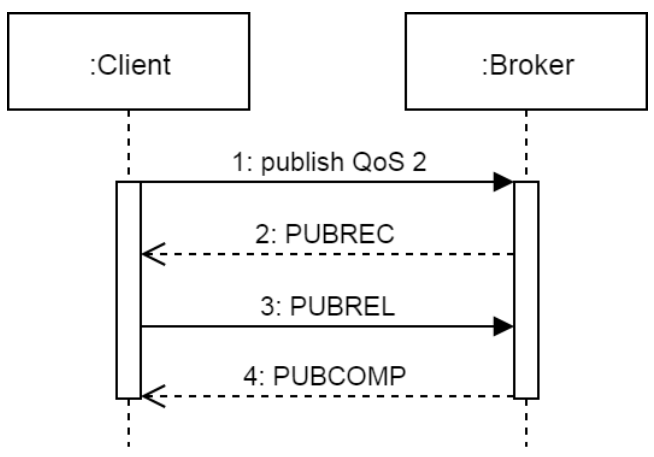

Рис. 2. Діаграма послідовності сценарію QoS 2

Дія трактується як діяльність надсилання повідомлень. 3 цією метою введено множину значень змінних стану:

$$
D=\left\{d_{1}, d_{2}, d_{3}\right\}
$$

де $d_{1}=0 \in D-$ повідомлення ще не надіслано, $d_{2}=1 \in D-$ повідомлення надіслано та його потрібно підтвердити, $d_{3}=2 \in D$ - повідомлення підтверджено.

Формування множини атомарних висловлювань.

Множина атомарних висловлювань є декартовим добутком множин (2) та (3):

$$
A P=V \times D .
$$

Ця концептуалізація трактує поняття «повідомлення» як елементарну конструкцію - показник деталізації. Він розглядається як площина нижчого рівня специфікації. Аспекти реалізації на основі TLA були описані раніше [24], [25].

Концептуалізація та формалізм PlusCal.

Однією з відмінних рис запропонованого підходу є використання алгоритмічної мови PlusCal, що зменшує вплив людського фактору у процесі синтезу специфікації [26]. Названий формалізм забезпечує компактне, структуроване і конфігуроване подання зазначених властивостей. 3 цією метою було використано концепт «мітка». Кожна мітка призначена для відображення відповідної властивості 3 прив'язкою до рівня QoS - 0, 1 та 2. Для створення специфікації PlusCal було використано інтегроване середовище розробки TLA Toolbox. Воно включає інструменти для автоматизованого синтезу більш деталізованої специфікації, що базується на формалізмі TLA+, з вихідної, більш абстрактної специфікації на алгоритмічній мові PlusCal.

Opiєнтуючись на компактність опису PlusCal, було обрано Сі-подібний синтаксис. Навіть більше, PlusCal забезпечує можливість варіювання рівня деталізації специфікації.

Таким чином, запропонований підхід можна охарактеризувати таким чином:

- $\quad$ створити специфікацію протоколу на основі формалізму PlusCal згідно виразів (2) - (4), де кожна мітка представляє відповідну властивість - верхню площину (рівень атомарності можна змістити);

- на основі специфікації PlusCal, створеної вручну, синтезувати відповідну деталізовану специфікацію на мові TLA+, використовуючи засоби інструментарію TLA Toolbox;

- перевірити синтезовану TLA+ специфікацію методом перевірки на моделі TLC. Часові витрати, пов'язані 3 верифікацією, можна охарактеризувати як задовільні [27], [28].

Проблему сумісності компонентів ІоТ-системи пропонується вирішувати 3 позиції перевірки узгодженості взаємодії останніх.

За основу узято специфікацію МQTT версії 3.1.1 [7]. Проведена перевірка на моделі підтвердила коректність реалізації властивості QoS рівня 2 протоколу MQTT - $з$ позиції узгодженості взаємодії компонентів.

Обговорення отриманих результатів. Практичне значення одержаних результатів полягає в можливості застосування запропонованого підходу з метою уникнення непередбачуваних сценаріїв взаємодії компонентів систем Інтернету речей, зокрема відмов взаємодії.

ВИСНОВКИ. Таким чином, в роботі проведено аналіз підходів до специфікації та верифікації протоколів ІоТ. За результатами проведеного аналізу запропоновано власний підхід. 
Одержано наступні результати:

1. Підходи до специфікації та верифікації протоколів ІоТ були класифіковані таким чином: підходи, спрямовані на оцінку ефективності реалізації, та підходи, спрямовані на пошук помилок у проектних рішеннях. Обгрунтовано важливість створення підходу, спрямованого на перевірку сумісності між компонентами системи ІоТ під час проектування шляхом перевірки на моделі.
2. Запропоновано підхід, заснований на темпоральній логіці TLA, формалізмах TLA + тa PlusCal та відповідному методі перевірки на моделі TLC, призначений для автоматизованої перевірки сумісності між компонентами системи ІоТ шляхом формальної верифікації. Специфіку підходу продемонстровано на прикладі протоколу MQTT.

Майбутня робота спрямована на автоматизацію процедури синтезу специфікацій мовою PlusCal.

\section{Список літератури}

[1] Li S., Xu L. D., Zhao S. 5G Internet of Things: a survey. Journal of Industrial Information Integration. 2018. Vol. 10. P. 1-9.

[2] Al-Fuqaha A., Guizani M., Mohammadi M., Aledhari M., Ayyash M. Internet of things: a survey on enabling technologies protocols and applications. IEEE Communications Surveys \& Tutorials. 2015. Vol. 17, No. 4. P. $2347-2376$.

[3] Bormann C., Castellani A. P., Shelby Z. CoAP: an application protocol for billions of tiny Internet nodes. IEEE Internet Computing. 2012. Vol. 16, No. 2. P. 62-67.

[4] Karagiannis V., Chatzimisios P., Vazquez-Gallego F., Alonso-Zarate J. A survey on application layer protocols for the internet of things. Transaction on IoT and Cloud Computing. 2015. Vol. 3, No. 1. P. 11-17.

[5] Al-Fuqaha A., Khreishah A., Guizani M., Rayes A., Mohammadi M. Toward better horizontal integration among iot services. IEEE Communications Magazine. 2015. Vol. 53, No. 9. P. 72-79.

[6] Thangavel D., Ma X., Valera A., Tan H.-X., Tan C. K.-Y. Performance evaluation of MQTT and CoAP via a common middleware. Intelligent Sensors, Sensor Networks and Information Processing : 2014 IEEE Ninth Int. Conf. (Singapore, April 2014). Singapore, 2014. P. 1-6.

[7] Information technology - Message Queuing Telemetry Transport (MQTT) v3.1.1, ISO/IEC 20922:2016, 2016. URL: https://www.iso.org/standard/69466.html (дата звернення: 10.11.2019).

[8] Organization for the advancement of structured information standards, "MQTT version 5.0," OASIS, Candidate OASIS Standard 01, 31 October 2018. URL: https://docs.oasis-open.org/mqtt/mqtt/v5.0/mqtt-v5.0.html (дата звернення: 10.11.2019).

[9] Light R. A. Mosquitto: server and client implementation of the MQTT protocol. Journal of Open Source Software. 2017. Vol. 2, No. 13. P. 1-2.

[10] Johnson J. E., Langworthy D. E., Lamport L., Vogt F. H. Formal specification of a web services protocol. Electronic Notes in Theoretical Computer Science. 2004. Vol. 105. P. 147-158.

[11] Hunkeler U., Truong H. L., Stanford-Clark A. MQTT-S - A publish/subscribe protocol for wireless sensor networks. Communication Systems Software and Middleware and Workshops : Proc. 2008 3rd International Conf. (Bangalore, India, Jan. 2008). Bangalore, 2008. P. 791-798.

[12] Houimli M., Kahloul L., Benaoun S. Formal specification verification and evaluation of the mqtt protocol in the internet of things. Mathematics and Information Technology : 2017 Int. Conf. (Adrar, Algeria, Dec. 2017). Adrar, 2017. P. 214-221.

[13] Lee S., Kim H., Hong D-K., Ju H. Correlation analysis of MQTT loss and delay according to QoS level. Information Networking : The Int. Conf. 2013 (Bangkok, Thailand, Jan. 2013). Bangkok, 2013. P. 714-717.

[14] Rodríguez A., Kristensen L. M., Rutle A. On modelling and validation of the MQTT IoT protocol for M2M communication. Petri Nets and Software Engineering : Int. Workshop (Bratislava, Slovakia, Jun. 2018). vol. 2138. P. 99-118.

[15] Diwan M., D’Souza M. A framework for modeling and verifying IoT communication protocols. Dependable Software Engineering: Theories, Tools, and Applications : Third Int. Symposium, part of LNCS (Changsha, China, Oct. 2017). vol. 10606. P. 266-280.

[16] Abrial J-R., Butler M., Hallerstede S., Hoang T. S., Mehta F., Voisin L. Rodin: an open toolset for modelling and reasoning in Event-B. Int. Journal on Software Tools for Technology Transfer. 2010. Vol. 12, No. 6. P. 447-466.

[17] Govindan K., Azad A. P. End-to-end service assurance in IoT MQTT-SN. Consumer Communications and Networking : 2015 12th Annual IEEE Conf. (Las Vegas, NV, USA, Jan. 2015). Las Vegas, 2015. P. $290-296$.

[18] Aziz B. A formal model and analysis of an IoT protocol. Ad Hoc Networks. 2016. Vol. 36, Part 1. P. 49-57.

[19] Tappler M., Aichernig B. K., Bloem R. Model-based testing IoT communication via active automata learning. Software Testing, Verification and Validation : 2017 IEEE International Conference (Tokyo, Japan, March 2017). Tokyo, 2017. P. 276-287.

[20] Vattakunnel A. J., Kumar N. S., Kumar G. S. Modelling and verification of CoAP over routing layer using SPIN model checker. Procedia Computer Science. 2016. Vol. 93. P. 299-308. 
[21] Lamport L. Specifying systems: The TLA+language and tools for hardware and software engineers. Boston : Addison-Wesley, 2002. 364 p.

[22] Newcombe C., Rath T., Zhang F., Munteanu B., Brooker M., Deardeuff M. How Amazon web services uses formal methods. Communications of the ACM. 2015. Vol. 58, No. 4, P. 66-73.

[23] Clarke E. M., Grumberg O., Peled D. A. Model checking. Massachusetts : MIT Press, 2001.

[24] Shkarupylo V., Polska O. The approach to SDN network topology verification on a basis of Temporal Logic of Actions. Advanced Trends in Radioelectronics, Telecommunications and Computer Engineering : 14th Int. Conf. (Lviv-Slavske, Ukraine, Feb. 2018). Lviv-Slavske, 2018. P. 183-186.

[25] Shkarupylo V., Kudermetov R., Golub T., Polska O., Tiahunova M. Towards model checking of the Internet of Things solutions interoperability. Problems of Infocommunications. Science and Technology : 2018 IEEE Int. Scientific and Practical Conf. (Kharkiv, Ukraine, Oct. 2018). Kharkiv, 2018. P. 465-468.

[26] Lamport L. The PlusCal algorithm language. Theoretical Aspects of Computing : 6th Int. Colloquium, part of LNCS, vol. 5684 (Kuala Lumpur, Malaysia, Aug. 2009). P. 36-60.

[27] Shkarupylo V. V., Tomicic I., Kasian K. M. The investigation of TLC model checker properties. Journal of Information and Organizational Sciences. 2016. Vol. 40, No. 1. P. 145-152.

[28] Shkarupylo V. V., Tomicic I., Kasian K. M., Alsayaydeh J. A. J. An approach to increase the effectiveness of TLC verification with respect to the concurrent structure of TLA+ specification. International Journal of Software Engineering and Computer Systems. 2018. Vol. 4, No. 1. P. 48-60. 